\title{
Representações Sociais do Desenvolvimento Humano
}

\author{
Angela Maria de Oliveira Almeida ${ }^{1}$ \\ Universidade de Brasilia \\ Gleicimar Gonçalves Cunba \\ Universidade Católica de Brasília
}

\begin{abstract}
Resumo
Nesse estudo, interessou-nos conhecer os elementos das representações sociais do desenvolvimento humano em suas diferentes fases. Foi realizado um estudo orientado metodologicamente pela Teoria do Núcleo Central. Um questionário de categorização foi preenchido por 210 educadores distribuídos em quatro subgrupos (60 educadores de crianças, 60 de adolescentes, 60 de adultos e 30 de idosos). Além dos elementos constituintes das representações de desenvolvimento, esse estudo permitiu-nos identificar sua organização interna. Nossos resultados mostram que a criança foi associada com brincadeiras, inocência e dependência; o adolescente com transformações no corpo, crises existenciais e sexualidade; o adulto com produtividade, trabalho, estabilidade e, o idoso com sabedoria e experiência.

Palavras-chave: Representações sociais; desenvolvimento humano; curso da vida.
\end{abstract}

Social Representations of Human Development

\begin{abstract}
The aim of this study was to identify elements of social representations about life-span development, guided by the Theory of the Central Core. A questionnaire was filled out by 210 educators, distributed in four groups (60 children educators, 60 adolescent educators, 60 adult educators and 30 senior citizen educators). The study allowed the idenfication of elements of social representations about development and its internal organization. The results indicated that the child was associated with games, innocence and dependence; the adolescent with body transformations, existencial crisis and sexuality; the adult with productivity, work, stability and the senior citizen with wisdom and experience.

Keywords: Social representations; human development; life-span.
\end{abstract}

A Teoria das Representações Sociais (TRS), desenvolvida no âmbito da Psicologia Social, tem oferecido um importante aporte teórico aos pesquisadores que buscam compreender os significados, e os processos neles imbricados, criados pelos homens para explicar o mundo e sua inserção dentro dele. Entretanto, em que pese o número de pesquisas realizadas, "muito ainda há que realizar para explicitar conceitos, clarear definições e estabelecer articulações com outros conhecimentos produzidos, tanto no interior da própria Psicologia quanto em outras áreas do conhecimento" (Almeida, Santos \& Trindade, 2000, p. 1).

É nessa perspectiva que vislumbramos o estabelecimento de um diálogo entre a psicologia popular ${ }^{2}$ e a TRS, já que ambas apresentam algumas proposições comuns: "a construção de 'teorias' normativas pelo senso comum e sua necessária inserção cultural, a centralidade da preocupação com a produção de sentidos, além da atenção voltada para a assimilação do conhecimento científico pelo pensamento social” (Almeida \& cols., 2000, p. 2).

\footnotetext{
${ }^{1}$ Endereço para correspondência: Universidade de Brasília, Instituto de Psicologia, Departamento de Psicologia Escolar e do Desenvolvimento. E-mail: aalmeida@unb.br

${ }^{2}$ Folk Psychology. Nossas reflexões a respeito terão como referência básica os escritos de Bruner (1997a, 1997b).
}

As teorias do senso-comum ou representações sociais (RS), como denominamos na TRS, ou teorias populares, como denominadas por Bruner, em sua Psicologia Popular, correspondem aos significados construídos nos enjeux psicossociais. Esses significados são compreendidos como constituídos pela e constitutivos da realidade social, sendo, portanto, explicativos e prescritivos da realidade social. Intimamente articuladas às teorias científicas, as RS ou as teorias populares submetem os conhecimentos elaborados pelas ciências a um processo de ressignificação, visto que são negociados e recriados no bojo das teorias populares.

Nessa perspectiva, a ciência é compreendida como uma instituição especializada, que tem a ambição de intensificar o papel de explicadora da realidade, definindo regras, através de seus modelos teóricos, que acabam, também, por especificar e prescrever as ações humanas.

Da idéia primitiva que caracterizava a criança como um ser humano imperfeito, inconcluso, portador de inúmeras deficiências que deveriam ser sanadas até se atingir a idade adulta, ou o que equivale dizer da oposição entre natureza-civilização (criança má porque maculada pelo pecado original e homem bom porque liberto pela razão), evoluímos para um conceito científico da natureza humana. As teorias do desenvolvimento humano vêm 
expressar tal evolução, substituindo a idéia divina do pecado original, que deveria ser extirpado, pela idéia científica de uma imaturidade, caracterizada pela impossibilidade de se postergar a gratificação (enfoque psicanalítico), ou de um egocentrismo, baseado na incapacidade de se descentrar (enfoque piagetiano), incrementando-se com as idéias de recompensa e punição, que visavam o abandono dos papéis infantis (behaviorismo). Tais teorias, elaboradas no seio da ciência psicológica, propõem-se, inicialmente, descrever a natureza humana e seus processos de transformação. Porém, como salienta Bruner (1997a), quando essas teorias se tornam formas de conhecimento aceitos e reapropriados pela cultura, elas conferem um status de realidade social aos processos que buscavam explicar e aos fatos sobre os quais se apoiaram para "comprovar" a justeza de seus pressupostos: "(...) uma vez aceitas no conhecimento implícito que constitui a cultura, teorias que eram científicas tornam-se tão definidoras da realidade, prescritivas e canônicas como as teorias psicológicas às quais substituíram" (Bruner, 1997a, p.141).

A cientificização do desenvolvimento humano, ao longo da vida, é acompanhada de um estatuto para cada uma das diferentes etapas que o compõem, o qual define normas, comportamentos e expectativas em relação a cada etapa, em consonância com os valores da sociedade, dos grupos sociais e das relações inter-grupais. As teorias do desenvolvimento são, assim, tomadas como "verdades", porque coerentes com os valores dos contextos culturais nos quais se inserem, sendo que é tal coerência que confere a essas teorias uma face moral, institucionalizando certas práticas, como, por exemplo, a distribuição dos indivíduos em curvas normais, ou nos chamados padrões nacionais de desenvolvimento. Como abandonar o conceito de desenvolvimento normal que enquadra os indivíduos em curvas padronizadas de tamanho, peso, desenvolvimento psicomotor, raciocínio abstrato, repertório verbal etc? Por acaso, conceitos tais como marcos ou estágios de desenvolvimento não estariam na base da institucionalização de idéias como anormalidade, marginalidade, exclusão, deficiência ou declínio? As teorias do desenvolvimento humano, apoiadas nos pressupostos desenvolvidos por Freud, Skinner, Piaget e Vygotsky, muito mais do que descrever, acabaram por constituir uma realidade social acerca da natureza humana, institucionalizando o processo de desenvolvimento em uma direção determinada.

Em sua reflexão sobre as teorias do desenvolvimento humano e cultura, Bruner (1997a) assume que ele próprio, enquanto psicólogo do desenvolvimento, deveria, de forma semelhante ao antropólogo, apropriar-se dos métodos etnográficos, indo a campo para mapear, junto a seus "informantes", as crenças populares acerca do desenvolvimento e relacioná-las com as teorias científicas, apontando para as transmutações por que passa o conhecimento quando apropriado e re-significado pela cultura.

Cunha (2000) chama atenção para o caráter normatizador da Psicologia do Desenvolvimento. A tipificação dos diferentes estágios de desenvolvimento, especificando cada idade da vida, acaba por definir o lugar social dos sujeitos dentro da sociedade, o que dá à Psicologia do Desenvolvimento o caráter de instituição que define regras e prescreve comportamentos. Ao desenvolvimento humano foi associada a idéia de que todo indivíduo passa por um processo dividido em etapas que se distinguem, sobretudo, pelo acúmulo de capacidades e habilidades, que atingem seu apogeu na idade adulta.

Contudo, se por um lado a Psicologia do Desenvolvimento foi marcada por concepções baseadas na existência de uma natureza psicológica específica para cada estágio da vida, por outro, ela tem sido, mais recentemente, influenciada pelas contribuições da Psicologia Popular e pelo referencial psicossocial de Moscovici, que reivindicam o papel do contexto sócio-cultural na construção das próprias categorias de infância, adolescência, vida adulta e velhice.

De acordo com a TRS, por exemplo, as representações sociais de infância não se separam das concepções de homem, de mundo, dos valores e normas vigentes em uma sociedade. D'Alessio (1990) sugere que as características físicas próprias das crianças, aliadas ao contexto sóciohistórico no qual estão inseridas, contribuem para a construção de uma representação de infância centrada na idéia de dependência. Essas especificidades físicas, por sua vez, implicam em um posicionamento social do adulto que se torna, então, seu tutor, seu responsável.

Ao analisar essa questão, Chombart de Lauwe e Neuerhahn (1989) destacam que à medida em que as sociedades foram se complexificando a criança foi adquirindo um status diferente. Considerada durante longo tempo como propriedade dos pais, ela assumiu um lugar distinto daquele de subalterno e inferior. A Convenção Francesa de 1893 abriu caminho em direção a uma nova atitude em relação aos direitos da criança, destituindo os pais de seus direitos de proprietários dos filhos, para tornaremse responsáveis por eles.

No século XX, a partir da institucionalização da Declaração Internacional dos Direitos da Criança, realizada em 1959, reiterou-se, mais uma vez, as responsabilidades e os papéis do adulto em relação à criança. Comportamentos e atitudes socialmente construídos adquiriram um caráter de lei, de tal forma que os cuidados dirigidos à infância deixaram de ser apenas manifestações afetivas espontâneas, arbitrárias, e passaram a ser regra da sociedade, até mesmo com mecanismos de controle ao seu cumprimento. 
Foi também no século XX que a adolescência adquiriu relevância social, tornando-se objeto de investigação científica e de representação social. Diferentemente da criança, concebida como sinônimo de dependência, ao adolescente foi associado um lugar de transição e, portanto, de transformações necessárias e anteriores à vida adulta. Em outras palavras, a adolescência pode ser compreendida como um período de transição, que como tal envolve reconstruções do passado e elaborações de projetos futuros. Muito próxima à vida adulta, essa fase do ciclo vital tem sido, recorrentemente, associada à idéia de emancipação, encargo este que tem contribuído para que o adolescente seja colocado à deriva, de forma que se espera dele a conquista da maturidade adulta como indício de conclusão de seu processo desenvolvimental.

Sem desmerecer as garantias e os avanços dos direitos da criança e do adolescente, e resguardados os direitos e prerrogativas inerentes ao adulto, não se observou, no mesmo intervalo de tempo, uma dinâmica social que assegurasse, como nas idades anteriores, os direitos dos idosos e, portanto, as responsabilidades da família e do Estado em relação a eles.

De acordo com Almeida (1999), a diminuição da natalidade, o desenvolvimento da Medicina e o crescente envelhecimento da população contribuíram para que a velhice se tornasse um objeto de representação social, de políticas públicas e de pesquisas científicas. A própria Psicologia do Desenvolvimento propôs, em seus primórdios, teorias explicativas dessa idade da vida, situandoa na fase de declínio biológico e, portanto, de limitações e disfuncionalidade.

Contudo, na década de 1970, sobretudo a partir das contribuições da perspectiva do life-span de Paul Baltes, a Psicologia passou a incluir a velhice no processo de desenvolvimento humano como uma fase que envolve não apenas perdas mas, também, ganhos, conquistas.

Socialmente, no entanto, ainda parece prevalecer a idéia de idoso associado a uma figura decadente, necessitada e, por isso, dependente. Tais concepções, segundo Almeida (1999), tiveram importantes implicações na estruturação da identidade do idoso, assim como nas práticas sociais a ele dirigidas. Confinado em locais à margem da sociedade (asilos, hospitais, casas de repouso), o velho tem sido representado como uma pessoa cansada, doente, debilitada, enfim improdutiva.

Enquanto conceitos socialmente construídos, as idades da vida resgatam e revelam as diferentes concepções de homem e, conseqüentemente, de desenvolvimento que estiveram presentes ao longo da história da civilização. As diferentes fases da vida tornam-se verdadeiras instituições sociais quando sistematizadas pelas teorias desenvolvimentais, elaboradas no âmbito da psicologia, as quais apresentam os Psicologia: Reflexão e Crítica, 2003, 16(1), pp. 147-155 marcos de desenvolvimento de forma seqüenciada, ordenada e gradual rumo a uma competência maior e à maturidade.

Como exemplos dessa visão progressista, podemos destacar a infância e a adolescência. Tutelados e "menorizados", a criança e o adolescente retratam o roteiro ao qual foram submetidos. Seu desenvolvimento segue um fluxo de aquisições, conquistas e habilidades previstas e esperadas, tanto assim que a representação da criança e do adolescente se baseia no raciocínio do "já chegou", "já conseguiu", ou do "ainda não consegue", "ainda não faz", "ainda não pode fazer" (Castro, 1996).

Essa discussão remete-nos, invariavelmente, à análise da construção científica da Psicologia do Desenvolvimento. Ancorada nos paradigmas científicos hegemônicos da primeira metade do século XX, a Psicologia destituiu o desenvolvimento de seu contexto sócio-histórico, negligenciando, por exemplo, as crenças sociais sobre o desenvolvimento e suas implicações no processo desenvolvimental efetivo dos sujeitos.

O estudo das representações sociais dos professores expressa uma tentativa de compreender a forma pela qual as crenças, os valores, as teorias, enfim, os pensamentos sociais se integram com as práticas sociais desses profissionais, e estas com o processo de desenvolvimento dos seus alunos.

Dessa forma, partindo-se do pressuposto de que "teorias implícitas" têm implicações importantes no processo do desenvolvimento humano, objetivou-se investigar os elementos constituintes das representações sociais dos professores sobre o desenvolvimento do homem em seu ciclo vital. Supomos que existem tendências em subestimar o desenvolvimento da criança e do idoso e em compreender a vida adulta como o "período ótimo" do desenvolvimento humano, visto que esta última fase corresponde às expectativas socialmente valorizadas. Tais teorias estariam em consonância com a Psicologia do Desenvolvimento que tem, tradicionalmente, privilegiado a infância e a adolescência como seus objetos de investigação e considerado tais fases como o "lugar" do desenvolvimento, que se completa quando atingida a vida adulta.

Como instrumental teórico-metodológico recorreu-se à Teoria do Núcleo Central de Abric (1994), buscando identificar o conteúdo das representações sociais de desenvolvimento humano e sua estrutura.

Em um estudo preliminar foram levantados os elementos constituintes das representações sociais do processo de desenvolvimento humano entre professores da Fundação Educacional do Distrito Federal (FEDF) que trabalhavam com crianças, adolescentes e adultos, e entre educadores da terceira idade ligados à Subsecretaria para Assuntos do Idoso (SAI). Os participantes desse estudo responderam a quatro perguntas, com as quais objetivávamos 
obter respostas às seguintes questões: 1) que elementos constituem a representação social de desenvolvimento? 2) quais os aspectos (biológico, social, afetivo, cognitivo, etc) considerados na representação social de desenvolvimento? 3) o desenvolvimento pode ser dividido em fases? 4) em quais fases o desenvolvimento é dividido?

Os resultados obtidos neste estudo preliminar foram utilizados na construção do instrumento do estudo que será aqui apresentado, o qual buscou conhecer o conteúdo das "teorias implícitas" do desenvolvimento humano construídas e partilhadas por educadores que trabalhavam com as diferentes idades da vida, bem como a estrutura de tais teorias.

\section{Método}

\section{Participantes}

Participaram desse estudo 180 professores da FEDF, selecionados conforme a série em que lecionava, ou seja, faixa etária com a qual trabalhava, e 30 profissionais ligados ao SAI. Os professores da FEDF foram subdivididos em três grupos proporcionais: grupo que trabalhava com crianças (jardim à $4^{\text {a }}$ série) - Grupo Infância $(n=60)$; grupo que trabalhava com adolescentes $\left(5^{\mathrm{a}}\right.$ série ao $3^{\circ}$ ano do ensino médio) - Grupo Adolescência $(n=60)$ e grupo que trabalhava com adultos (supletivo) - Grupo Adulto $(n=60)$. O grupo de sujeitos que trabalhava com a terceira idade - Grupo Velhice - constituiu-se de 30 profissionais coordenadores de grupos de convivência de idosos (menos representado neste estudo em razão do número reduzido de profissionais que se dedicam ao trabalho com idosos).

Dentre os sujeitos do Grupo Infância, 10 eram do sexo masculino (16,7\%) e 50 do sexo feminino (83,3\%). A idade média desse grupo era de 30,02 anos. Já o Grupo Adolescência era composto por $40 \%$ de sujeitos do sexo masculino e $60 \%$ do sexo feminino. Sua idade média era de 35,7 anos. O Grupo Adulto apresentou uma porcentagem de 63,3\% de professoras e de $36,7 \%$ de professores. A idade média desse grupo era de 34,6 anos. Por último, o Grupo Velhice tinha $80 \%$ de sujeitos do sexo feminino e $20 \%$ do sexo masculino, com idade variando essencialmente entre 40 e 59 anos.
Além do sexo e da idade dos sujeitos, foram levantados os seguintes dados sócio-demográficos: nível de escolaridade e tempo de magistério.

Como pode ser observado na Tabela 1 , a grande maioria dos sujeitos apresentam nível superior de escolaridade. Em relação ao tempo de magistério, observou-se a coincidente média de 9,7 anos tanto para o Grupo Adolescência quanto para o Grupo Adulto. Vale destacar que muitos dos professores habilitados para a docência em ensino médio/ supletivo também o são para o ensino fundamental. $\mathrm{O}$ Grupo Infância apresentou uma média de 6,7 anos de tempo de magistério. O Grupo Velhice foi liberado dessa pergunta, já que seu trabalho não se caracteriza, necessariamente, como magistério.

\section{Instrumento}

Foi utilizado como instrumento de coleta de dados um questionário construído a partir dos resultados obtidos no estudo preliminar. Esse instrumento compunha-se de duas partes, uma referente ao objeto de pesquisa propriamente dito e outra ao levantamento dos dados sócio-demográficos dos sujeitos. A primeira parte do instrumento - questionário de categorização- continha 6 questões. $O$ presente artigo restringir-se-á à apresentação dos resultados relativos a duas questões $\left(1^{\mathrm{a}}\right.$ e $\left.6^{\mathrm{a}}\right)$. Na primeira questão foi solicitado ao sujeito que agrupasse, a partir de uma lista de 25 itens, palavras e expressões que melhor caracterizavam a infância, a adolescência, a vida adulta e a velhice.

Para se verificar a hipótese de que a fase adulta corresponde ao período "ótimo" do desenvolvimento, foi apresentada uma última questão aos sujeitos, a qual solicitava a seguinte avaliação: "Se você tivesse que dizer que uma pessoa está mais ou menos desenvolvida, você faria sua avaliação tomando como referência qual fase do desenvolvimento em geral?’'

\section{Procedimento de coleta e análise dos dados}

Os dados foram coletados nos locais de trabalho dos sujeitos, respeitando-se sua disponibilidade. Os instrumentos foram, em sua maioria, aplicados individualmente. No caso dos idosos, foi necessário a coleta de dados em suas residências, pois os mesmos encontravam-se em período de férias.

Tabela 1

Distribuição dos Sujeitos em Função do Grau de Escolaridade $(N=210)$

\begin{tabular}{|c|c|c|c|c|c|c|c|c|c|c|}
\hline & \multicolumn{10}{|c|}{ Grupos } \\
\hline & \multicolumn{2}{|c|}{$\begin{array}{l}\text { Grupo } \\
\text { infância }\end{array}$} & \multicolumn{2}{|c|}{$\begin{array}{c}\text { Grupo } \\
\text { adolescência }\end{array}$} & \multicolumn{2}{|c|}{$\begin{array}{l}\text { Grupo } \\
\text { adulto }\end{array}$} & \multicolumn{2}{|c|}{$\begin{array}{l}\text { Grupo } \\
\text { velhice }\end{array}$} & \multicolumn{2}{|c|}{ Total } \\
\hline Curso superior & $f$ & $\%$ & $f$ & $\%$ & $f$ & $\%$ & $f$ & $\%$ & $f$ & $\%$ \\
\hline Sim & 50 & 83,3 & 60 & 100 & 60 & 100 & 12 & 40,0 & 182 & 86,7 \\
\hline Não & 09 & 15,0 & - & - & - & - & 09 & 30,0 & 18 & 8,6 \\
\hline Não respondidos & 01 & 1,7 & - & - & - & - & 09 & 30,0 & 10 & 4,7 \\
\hline Total & 60 & 100 & 60 & 100 & 60 & 100 & 30 & 100 & 210 & 100 \\
\hline
\end{tabular}


Para a análise das respostas obtidas na $1^{a}$ questão (grupo de palavras), foi utilizado o software SIMI, o qual permitiu averiguar que tipo de relação os elementos constituintes da representação social de desenvolvimento mantém entre si.

A análise de similitude é fruto de um trabalho que vem sendo realizado desde 1962 por Flament, Degenne e Vergès. Esses autores adotam os seguintes pressupostos: a) uma representação social corresponde a um conjunto de cognomes organizado por múltiplas relações; b) essas relações podem ser orientadas (implicação, causalidade hierarquia...), ou simétricas (equivalência, semelhança, antagonismo...), mas todas podem se "degradar" em uma relação simétrica traduzindo a idéia vaga de "ir junto" e c) essas relações, em geral, não são transitivas: se A vai com B por certas razões, $\mathrm{e}$ $\mathrm{B}$ com $\mathrm{C}$ por outras, pode ser que $\mathrm{A}$ e $\mathrm{C}$ não tenham alguma razão de se associarem (Flament, 1986).

O referido método de análise dos dados corresponde, portanto, à idéia de que os elementos constituintes da representação social mantém entre si uma relação simétrica não transitiva, denominada por Flament (1986) pelo termo relação de similitude. Essa relação, por sua vez, designa o fato de dois cognomes associarem-se no interior de uma dada representação social.

O autor admite que dois itens serão mais próximos na representação quanto maior for o número de sujeitos que os tratem da mesma maneira (seja os que aceitam os dois, seja os que os rejeitem). A partir desse pressuposto, calcula-se um índice de contingência - indice de similitude clássica.

Esse procedimento de análise resulta na construção de grafos ilustrativos das relações estabelecidas entre os elementos da representação. De acordo com Flament (1986), esses grafos podem ser do tipo: árvore máxima (ilustra o cruzamento entre todos os termos da representação que mantém algum tipo de relação entre si); grafos com filtro (revela todas as ligações entre os termos propostos que foram efetuadas por pelo menos um e outro dentro da porcentagem de sujeitos considerada); ou grafos de relações significativas (permite a visualização das relações entre os termos mais característicos da representação para um dado grupo de sujeitos). No presente estudo foram construídos grafos do tipo árvore máxima, com indicativos dos pesos correspondentes aos respectivos elementos ${ }^{3}$.

Para a análise dos dados obtidos na $6^{\mathrm{a}}$ questão (testagem da hipótese de que o desenvolvimento culmina com a fase adulta) recorreu-se a cálculos quantitativos simples.

\section{Resultados e Discussão}

Os resultados serão descritos e discutidos conforme o grupo de sujeitos considerados, visto que as respostas foram analisadas comparativamente. Para cada grupo de educadores será apresentado, portanto, sua avaliação sobre o desenvolvimento humano ao longo de todo o ciclo vital, a partir da análise de similitude dos agrupamentos de palavras. Por último, os resultados da $6^{a}$ questão serão apresentados, averiguando-se em que medida a fase adulta é tomada como referência no processo de desenvolvimento do ser humano.

\section{Representação social do desenvolvimento pelos sujeitos do Grupo} Infância

Da análise de similitude a que foram submetidas as respostas dos sujeitos do Grupo Infância, extraiu-se o grafo tipo árvore máxima, mostrando todas as ligações entre os termos propostos efetuadas por um ou outro do total de sujeitos (Figura 1).

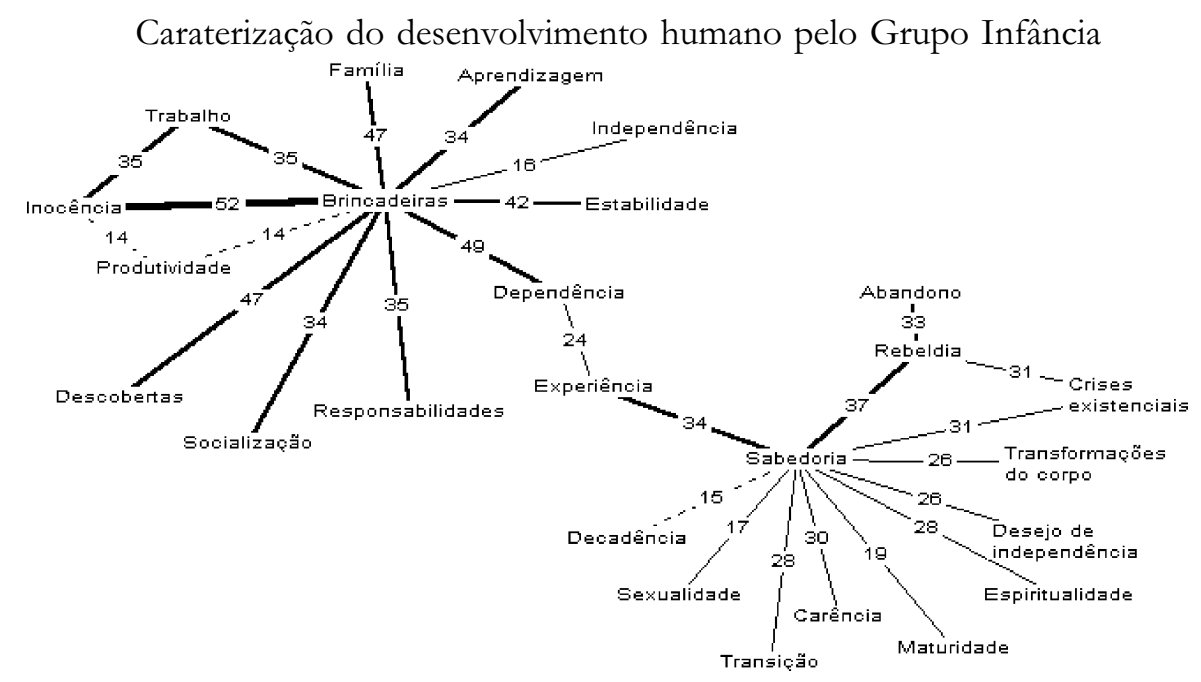

Figura 1. Árvore máxima da representação social de desenvolvimento humano elaborada pelo Grupo Infância $(n=60)$.

${ }^{3}$ As análises foram realizadas no LAPES/IP/UnB, sendo que para esse procedimento contamos com a preciosa colaboração de Aldry Sandro Monteiro Ribeiro e do Prof. Dr. Pedro Humberto Farias Campos 
Esse grafo revela uma visão progressista de desenvolvimento. Ao apontar os elementos "brincadeira" e "sabedoria" como os dois grandes eixos organizadores da representação social de desenvolvimento, a figura nos indica o quanto esse processo tem sido concebido à luz da visão teleológica-evolutiva.

Percebe-se que, embora o elemento "brincadeira" esteja associado aos termos "trabalho", "responsabilidades", "estabilidade", "independência", e, com um peso menos significativo, "produtividade", a visão subjacente à infância, particularmente, consiste naquela discutida e exemplificada pela literatura. Associada à idéia de imaturidade e de "incompletude", a criança "inocente" "brinca", "aprende", "descobre", mas "depende", de sua "familia". Seus pais adultos "trabalham", "produzem" e se "responsabilizam" por ela.

Essa leitura ilustra o lugar social ao qual a criança foi designada. Ideologicamente considerada como objeto de proteção e cuidados, a criança deve ser tutelada e estar sob a custódia de alguém idealmente preparado para responder as suas necessidades tanto físicas, como afetivas e educacionais. Enquanto sujeito desprovido, a criança é considerada como ainda não plenamente agente, competente e responsável.

Representação social do desenvolvimento pelos sujeitos do Grupo Adolescência

A análise de similitude para esse grupo de sujeitos resultou no grafo a seguir, conforme ilustra a Figura 2.

Para o grupo de educadores que trabalham com a adolescência, as representações sociais do desenvolvimento humano estruturam-se de forma muito similar às representações forjadas pelos educadores do Grupo Infância. Os elementos centrais parecem ser "brincadeiras", "família" e "sabedoria".

Paradoxalmente, o grupo de educadores que se ocupa profissionalmente de adolescentes (assim como o Grupo Infância) não ressalta, em suas representações, o caráter particular dessa fase do desenvolvimento. Ao contrário, termos que nos remetem habitualmente à adolescência (e reiterados em outras questões desse estudo) foram associados àqueles que caracterizam a velhice. Tudo se passa como se a lógica que enquadra o adolescente à idéia do "ainda não consegue", "ainda não faz", e o velho à idéia de que "já não consegue mais", "já não faz mais", implicasse em uma desresponsabilização do adulto com essas fases da vida, ao contrário do que se opera com a infância. Percebese que nesta perspectiva, a infância, tal como retratada nas Figuras 1 e 2, é muito mais caracterizada pelo papel do adulto em relação a essa fase da vida (trabalho, produtividade, socialização, dependência da criança em relação ao adulto independente, responsabilidade, estabilidade), do que propriamente por seus atributos particulares (inocência, brincadeiras, descobertas e aprendizagem).

Representação social do desenvolvimento pelos sujeitos do Grupo Adulto

Para o Grupo Adulto, a representação social de desenvolvimento humano estrutura-se em torno de dois grandes eixos: "brincadeiras" e "sabedoria". No grafo (Figura 3) observa-se uma caracterização muito próxima daquelas atribuídas pelos Grupos Infância e Adolescência.

Caraterização do desenvolvimento humano pelo Grupo Adolescência

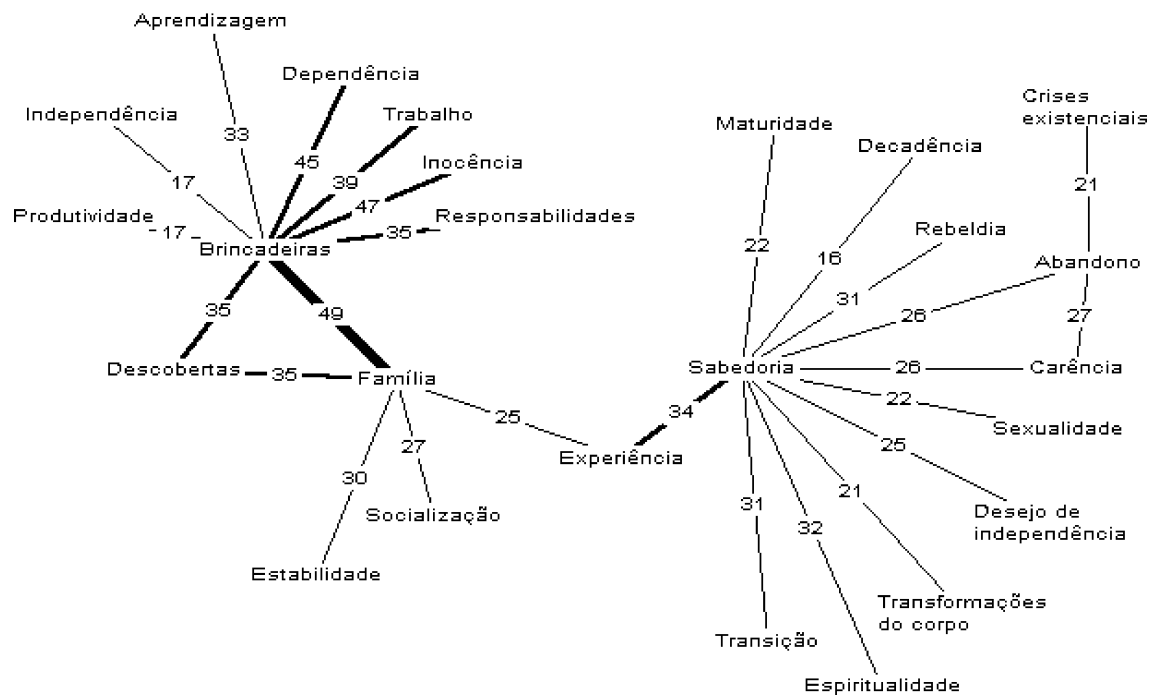

Figura 2. Árvore máxima da representação social de desenvolvimento humano elaborada pelo Grupo Adolescência $(n=60)$. 
O desenvolvimento é compreendido por esses educadores como um processo que se inicia em uma fase mais simples, que demanda aos adultos cuidados e atenção (infância) e prossegue para uma fase onde o sujeito já adquiriu sua independência (adulto), ou está em processo de emancipação (adolescente). Embora associado à figura de uma pessoa "sábia", "experiente", “espirituosa", "madura”, o idoso parece demarcar a fase do não-desenvolvimento, da decadência, e, conseqüentemente, do abandono.

Novamente configura-se uma visão progressista de desenvolvimento, que pressupõe um fluxo de crescente complexidade até a vida adulta e um declínio que se inicia na velhice

Representação social do desenvolvimento pelos sujeitos do Grupo Velbice

Como se pode perceber (Figura 4), diferentemente dos três primeiros grupos, os elementos estruturantes da representação social do desenvolvimento humano ao longo da vida pelo Grupo Velhice foram: "brincadeiras", "dependência", "família" e "trabalho". Observa-se que desses 4 elementos, os dois primeiros caracterizam particularmente a infância, enquanto os 2 últimos, a vida adulta. Constata-se que o grupo dos idosos tende a negar a presença de desenvolvimento durante a velhice, como se a vida se encerrasse na fase adulta, quando o adulto assume suas responsabilidades junto à família, garantindo a subsistência de seus membros através do trabalho. Tal representação assemelha-se aos pressupostos das teorias psicológicas do desenvolvimento humano, as quais situaram, durante muito tempo, apenas na infância e na adolescência os processos de desenvolvimento.
Pode-se, ainda, supor que o Grupo Velhice, por ter sido constituído por adultos e idosos, apresenta uma representação caracterizada pela negação da identidade socialmente construída para o idoso - indivíduo decadente. Porém, ao mesmo tempo que se opõem à idéia de idoso como sujeito decadente, vitimizam-no, na medida em que o tratam como um sujeito abandonado e carente, cujos membros de sua família estão preocupados em trabalhar e produzir para atender, sobretudo, as necessidades das crianças.

O desenvolvimento para o Grupo Velhice não culmina com a "experiência", "espiritualidade" e "sabedoria" do idoso, mas com o trabalho do adulto. A velhice foi associada à vida adulta, talvez porque os educadores pertencentes a esse grupo lidavam com uma realidade diferente daquela representada pelos demais sujeitos desta pesquisa. Tratavase de profissionais, em sua grande maioria, aposentados, mas ainda em atividade como coordenadores dos grupos de convivência de idosos.

Lembrando que em geral o exercício profissional, as responsabilidades, enfim o trabalho são associados ao adulto, parece plausível supor que, como sujeitos engajados na luta por uma melhor qualidade de vida para o idoso, esses educadores adotam a vida adulta como referência identitária para a velhice.

Fase da vida tomada como referência para avaliação do desenvolvimento bumano

As respostas à questão relacionada à hipótese de que o ponto optimal do desenvolvimento se circunscreve na vida adulta estão descritas na Tabela 2.

Os dados da tabela confirmam a hipótese inicial de que a fase adulta seria a fase ótima do desenvolvimento.

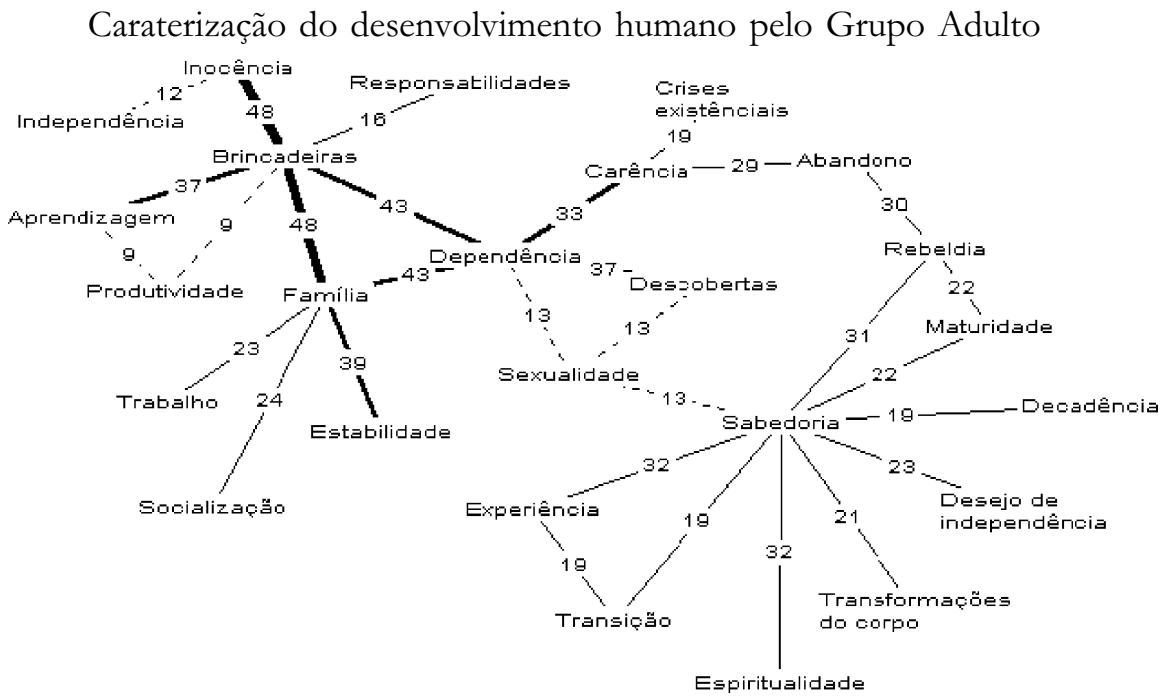

Figura 3. Árvore máxima da representação social de desenvolvimento humano elaborada pelo Grupo Adulto ( $n=60$ ). 
Com uma freqüência superior em relação às outras fases, a vida adulta foi apontada por 58,6\% dos sujeitos da amostra total como o momento referência para avaliação das demais etapas da vida. Isso evidencia que os educadores não tomavam como critérios de avaliação do desenvolvimento de seus alunos as características próprias da fase com a qual trabalhavam, mas habilidades, conquistas, comportamentos referentes à vida adulta.

A partir da discussão teórica deste estudo, pode-se afirmar que o desenvolvimento humano tem sido compreendido, pelos educadores dessa pesquisa, como um processo marcado pela vida adulta. Essa leitura reitera a idéia de que a infância e a adolescência correspondem às fases do "ainda não consegue" e a velhice, por sua vez, à etapa do "já não consegue mais".

Essa visão desenvolvimental implica em uma postura de desqualificação das conquistas de cada sujeito no decorrer de todo o seu ciclo vital (com exceção do adulto), visto que o "não consegue" e o "não consegue mais" indicam "atrasos/perdas desenvolvimentais" frente ao universo adulto, por evidenciarem a falta dos domínios e competências relativos à vida adulta.

\section{Conclusão}

Os resultados desse estudo evidenciam as bases científicas do conhecimento popular acerca do desenvolvimento humano, caracterizadas por uma visão normativa que pressupõe uma seqüência invariável de estágios, de caráter universal, irreversível, evoluindo de forma progressiva, para uma complexidade crescente até a vida adulta.

Nessa perspectiva, a Psicologia, ao inserir a vida humana dentro de um arcabouço científico, uniformizou a trajetória da vida, dando-lhe uma direção e uma finalidade. Os resultados encontrados mostram como a visão teleológica presente no pensamento psicológico perpassa o pensamento social: o desenvolvimento foi considerado como um fluxo de crescente aquisição até a vida adulta e de franca decadência na velhice. Estruturado em torno de dois grandes eixos - infância e velhice -, o conhecimento popular acerca do desenvolvimento define o lugar social reservado aos sujeitos em cada etapa de sua vida. $\mathrm{Na}$ infância, as crianças devem, sob a proteção dos adultos, brincar, fazer novas descobertas, experimentar, visando adquirir novas competências, as quais as preparam para uma vida adulta. De forma semelhante, ao adolescente é autorizado, pelas mudanças biológicas por que passam seu corpo, experimentar sua sexualidade, tentar seus primeiros vôos de independência, e vivenciar, em suas crises existenciais, seus acertos e erros, preparando-se para uma vida adulta. Ao adulto, é assegurado o espaço do trabalho, da produtividade, que lhe assegura o papel de tutor, do responsável pelos seus descendentes e, portanto, de referência para as outras fases da vida. Ao velho, só resta transmitir a sabedoria acumulada ao longo da vida, para amenizar as marcas da decadência e do declínio que se anunciam através das perdas biológicas.

Tais representações confirmam os assinalamentos tecidos anteriormente. $\mathrm{Na}$ medida em que as teorias científicas do desenvolvimento são incorporadas à cultura, elas são valoradas e institucionalizadas, assumindo uma face moral, com implicações importantes nas práticas sociais. As teorias implícitas do desenvolvimento humano, partilhadas por nossos educadores que trabalham com crianças, adolescentes, adultos e idosos, revelam em si a face moral que o significado da natureza humana assume na sociedade moderna. $\mathrm{O}$ indivíduo, assujeitado em seu processo de desenvolvimento, vive as regras da sociedade neo-liberal: o homem é tanto melhor quanto maior for seu mérito, o qual é definido pelas riquezas que acumula usando sua capacidade produtiva - o trabalho. De forma semelhante, a face moral das teorias populares é revelada por Moscovici (1961), ao identificar, no esquema figurativo da psicanálise, representações que comportam os conceitos de consciente, inconsciente, recalque e complexo, mas que elimina a idéia de libido, em razão de sua associação com a sexualidade.

A força dessas idéias, transformando-as em verdadeiras instituições, evidencia-se quando elas assumem o papel de moduladoras das práticas educativas. No âmbito pedagógico, as ações desenvolvidas junto aos sujeitos, nas diferentes etapas de suas vidas, ligam-se muito mais à formação para o trabalho e para a produção do que à realização plena do sujeito, de acordo com suas possibilidades, em cada fase da vida.

As teorias do desenvolvimento, quando incorporadas pela cultura, passam a se constituir em elementos do imaginário que dão organicidade aos grupos sociais e que definem os espaços designados a cada indivíduo em uma dada configuração social, participando, assim, da construção de suas identidades.

Quando resgatamos, por exemplo, o grafo referente à representação social de desenvolvimento pelo Grupo Velhice (Figura 4), compreendemos porque esses educadores, em sua grande maioria idosos, tendem a negar essa fase da vida, como se ela não correspondesse a uma fase do desenvolvimento humano. Associado à idéia de "decadência" e "dependência", o idoso procura salvaguardar sua identidade, negando tais atributos e, para tanto, recorre à ocultação de sua própria fase. Esse mecanismo psicológico parece funcionar para o idoso, em última instância, como estratégia para "manter-se vivo", visto que a ele foram tributadas características que denotam estagnação, fixismo, "morte". 
As representações dessa fase da vida assemelham-se às representações do mundo infantil. Representada como um ser pueril e lúdico, a criança não tem capacidade para se responsabilizar por si mesma, necessitando, como o idoso, do apoio adulto. A "dependência" torna-se, assim, um elemento estruturante das representações do desenvolvimento dessas duas fases da vida, ao mesmo tempo em que define o "lugar" do adulto no processo de desenvolvimento ao longo da vida. É na vida adulta que se assume a responsabilidade do trabalho, da constituição de uma família, a qual se torna, por excelência, o local de proteção da infância e da velhice.

Tudo indica, no entanto, que quanto mais próximo o sujeito está da vida adulta, menos proteção ele evoca e mais exigentes os adultos se tornam em relação a ele (Almeida \& Santos, 1998). Ao contrário, portanto, do que se passa com a criança e o idoso, a adolescência, fase mais próxima da vida adulta, é representada como um período de transição e preparação para um futuro próximo. Como pode-se constatar (Figuras 1, 2, 3 e 4), as transformações corporais, as descobertas sexuais e as crises existenciais apontam para uma representação do "não ser": o adolescente, que se encontra em processo de transição e mudança, "ainda não está" física e psicologicamente preparado para a vida adulta.

Nesse contexto, resta à vida adulta o lugar de "ápice do desenvolvimento", o que foi referendado pelos resultados obtidos a partir da última questão do instrumento, quando $58,6 \%$ dos educadores tomaram a fase adulta como o ponto de referência para a avaliação de todas as fases do desenvolvimento humano. Nessa perspectiva, pode-se afirmar que no âmbito das representações sociais do desenvolvimento ao longo da vida, a fase adulta se constitui o "ponto ótimo do desenvolvimento humano".

A representação da vida adulta como a fase referência do devir humano implica em uma desconsideração das especificidades dos sujeitos em cada fase da vida, substituindo-as por características valorizadas pela sociedade, as quais visam, sobretudo, as condições necessárias para a produção: trabalho, responsabilidade, maturidade e estabilidade.

Em última instância, fica implícito que as prerrogativas da vida adulta correspondem a objetivos definidos pela própria sociedade e designam o ápice do desenvolvimento. De sujeito ativo e participante de nosso devir, tornamonos objetos das normas e regras sociais, materializadas nas ações pedagógicas. Assim, se o curso de nosso desenvolvimento corresponde a uma gradual seqüência de aquisições previamente instituídas, visando um futuro produtivo na sociedade, corremos o risco de padecermos de nossa história, ao invés de construí-la.

\section{Referências}

Abric, J-C. (1994). L'organization interne des représentations sociales: Système central et système péripherique. Em C. Guimelli (Org.), Structures et transformation des représentations sociales (pp. 73-84). Lausanne: Delachaux et Niéstle.

Almeida, A. M. O. \& Santos, M. F. S. (1998, setembro). Les représentations $d u$ développement: L'enfant, l'adolescent et les personnes âgées. Trabalho apresentado na IV Conferência Internacional Sobre Representações Sociais, México.

Almeida, A. M. O. (1999). A trama da vida: Maturidade e gênero. Humanidades, $48,120-131$.

Almeida, A. M. O., Santos, M. F. S. \& Trindade, Z. A. (2000, maio). As práticas sociais como objeto de estudo: Contribuições teóricas e dificuldades metodológicas. Trabalho apresentado no VIII Simpósio da ANPEPP, Serra Negra.

Bruner, J. (1997a). Realidade mental, mundos possiveis (M.A.G. Domingues, Trad.) Porto Alegre: Artes Médicas. (Original publicado em 1986)

Bruner, J. (1997b). Atos de significação (S. Costa, Trad.). Porto Alegre: Artes Médicas. (Original publicado em 1990)

Castro, L. R. (1996). O lugar da infância na modernidade. Psicologia: Reflexão e Crítica, 9(2), 307-335.

Chombart de Lauwe, M-J. \& Feuerhahn, N. (1989). La représentation sociale dans le domaine de l'enfance. Em D. Jodelet (Or.), Les représentations sociales (pp. 320-340). Paris: PUF.

Cunha, G. G. (2000). Brincadeira, sexualidade, trabalho e sabedoria: Assim definem nosso desenvolvimento. Dissertação de Mestrado não-publicada, Curso de Pós-Graduação em Psicologia. Universidade de Nacional de Brasília. Brasília, DF.

D’Alessio, M. (1990). Social representations of childhood: An implicit theory of development. Em G. Duveen \& B. Lloyd (Org), Social representations and the development of knowledge (pp. 70-90). Cambridge: Cambridge University Press.

Flament, C. (1986). L'analyse de similitude: Une téchnique pour les recherches sur les représentations sociales. Em W. Doise \& A Palmonari (Orgs.), L'étude des représentations sociales (pp. 139-156). Neuchâtel, Paris: Delachaux et Niéstle.

Moscovici, S. (1961). La psycanalise, son image et son public. Paris: PUF.

Sobre as autoras

Angela Maria de Oliveira Almeida é Doutora pela Université Catholique de Louvain e Professora do Instituto de Psicologia da Universidade de Brasília.

Gleicimar Gonçalves Cunha é Mestre pelo Programa de Pós-graduação do Instituto de Psicologia

da Universidade de Brasília e Professora da Universidade Católica de Brasília.

Psicologia: Reflexão e Crítica, 2003, 16(1), pp. 147-155 


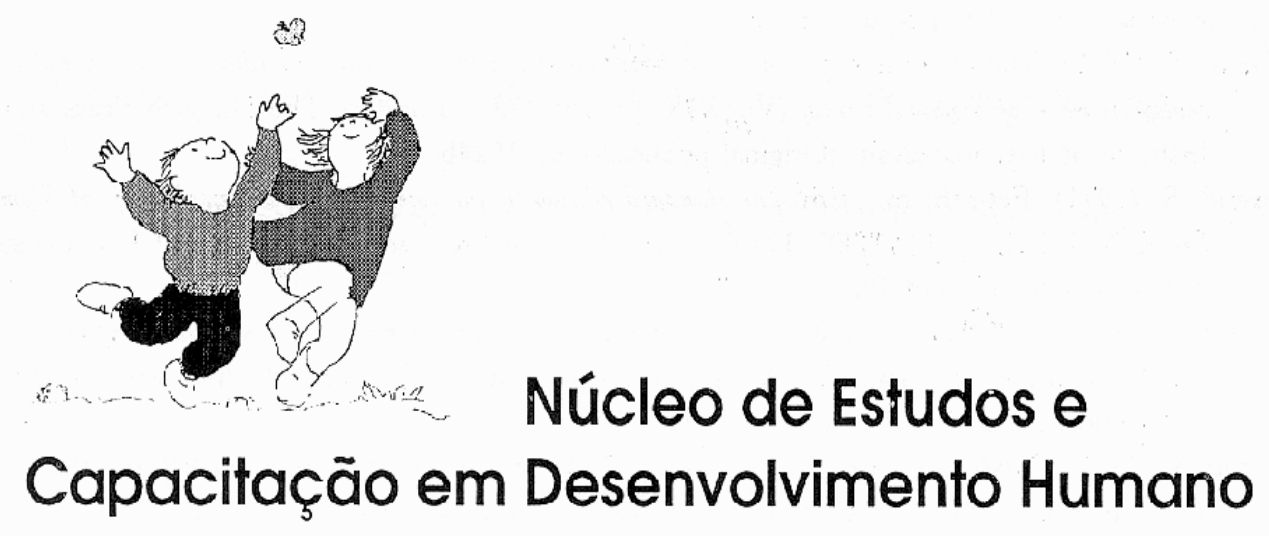

Objetivo Geral: Implementar a formação em

Desenvolvimento Humano de profissionais, técnicos, agentes de comunidade e estudantes das áreas de Educação e Saúde, através de discussões teórico-temáticas, dinâmicas pedagógicas e produção de material pedagógico.

NECADEH - CEP-RUA

Instituto de Psicologia

Rua Ramiro Barcelos, 2600, Sala 104

90035.003, Porto Alegre, RS

Fones: (51) 3165150/3309507 Fax: (51) 3304797 